\title{
Mode-Locked Semiconductor Lasers for Optical Communication Systems
}

\author{
Yvind, Kresten; Larsson, David; Oxenløwe, Leif Katsuo; Hvam, Jørn Märcher
}

Published in:

Proceedings of 2005 7th International Conference on Transparent Optical Networks

Link to article, DOI:

10.1109/ICTON.2005.1506135

Publication date:

2005

Document Version

Publisher's PDF, also known as Version of record

Link back to DTU Orbit

Citation (APA):

Yvind, K., Larsson, D., Oxenløwe, L. K., \& Hvam, J. M. (2005). Mode-Locked Semiconductor Lasers for Optical Communication Systems. In Proceedings of 2005 7th International Conference on Transparent Optical Networks (Vol. 2, pp. 209-212). IEEE. https://doi.org/10.1109/ICTON.2005.1506135

\section{General rights}

Copyright and moral rights for the publications made accessible in the public portal are retained by the authors and/or other copyright owners and it is a condition of accessing publications that users recognise and abide by the legal requirements associated with these rights.

- Users may download and print one copy of any publication from the public portal for the purpose of private study or research.

- You may not further distribute the material or use it for any profit-making activity or commercial gain

- You may freely distribute the URL identifying the publication in the public portal 


\title{
Mode-Locked Semiconductor Lasers for Optical Communication Systems
}

\author{
K. Yvind, D. Larsson, L. K. Oxenløwe, J. Mørk, and J. M. Hvam \\ Research Center COM, NanoDTU, Technical University of Denmark \\ Ørsteds Plads 345V, DK-2800 Kgs. Lyngby \\ Tel: (+45) 4525 6366, Fax: (+45) 45936581, e-mail:ky@com.dtu.dk
}

\section{ABSTRACT}

We present investigations on 10 and $40 \mathrm{GHz}$ monolithic mode-locked lasers for applications in optical communications systems. New all-active lasers with one to three quantum wells have been designed, fabricated and characterized.

Keywords: mode-locked semiconductor lasers, epitaxial design, noise, optical communication systems.

\section{INTRODUCTION}

In order for ultra-high speed optical communication systems, using time division multiplexing and optical signal processing, to be employed in future transmission networks, compact and integratable semiconductor components need to be developed. The key component to provide the large bandwidth is the mode-locked laser. In the transmitter, the short-pulse (wide bandwidth) laser can be directly synchronized to a sinusoidal (narrowband) electrical clock, and it can then provide all the timing functions, such that the requirements on the electrical components, modulators etc. are strongly relaxed. Later in the network, a low-frequency clock can be extracted when the laser is synchronized to the bitstream using a suitable clock-recovery scheme, an example of which will be shown in the end of this paper. Early studies [1] indicated that all-active monolithic semiconductor lasers would contribute too much excess noise compared to e.g. external cavity lasers and this could limit their usefulness. However, in this paper we will show that even very simple semiconductor monolithic mode-locked lasers (MMLLs) are able to deliver very good noise performance.

\section{DEVICE DESIGN}

The devices investigated are simple ridge waveguide single growth-step Fabry Perot lasers with two electrical contacts as shown in Fig. 1 (left). The design rules presented below will also be applicable to more complex lasers with DBR gratings and repetition rate tuning sections as needed for applications in real communication systems.

In the mode-locked laser, a pulse circulates in the optical cavity with a dynamic broadening in the gain section and a corresponding pulse shortening in the absorber. The main part of the broadening is due to gain saturation that also results in nonlinear chirp across the pulse [2]. One way of keeping the pulses short is by using a strong absorber to absorb the leading part of the pulse. This, however, introduces excess loss which reduces the efficiency of the laser and, more importantly, increases the noise and instabilities of the laser. A better approach is to design the gain section such that the pulse broadening is reduced and the requirement for reshaping is relaxed.
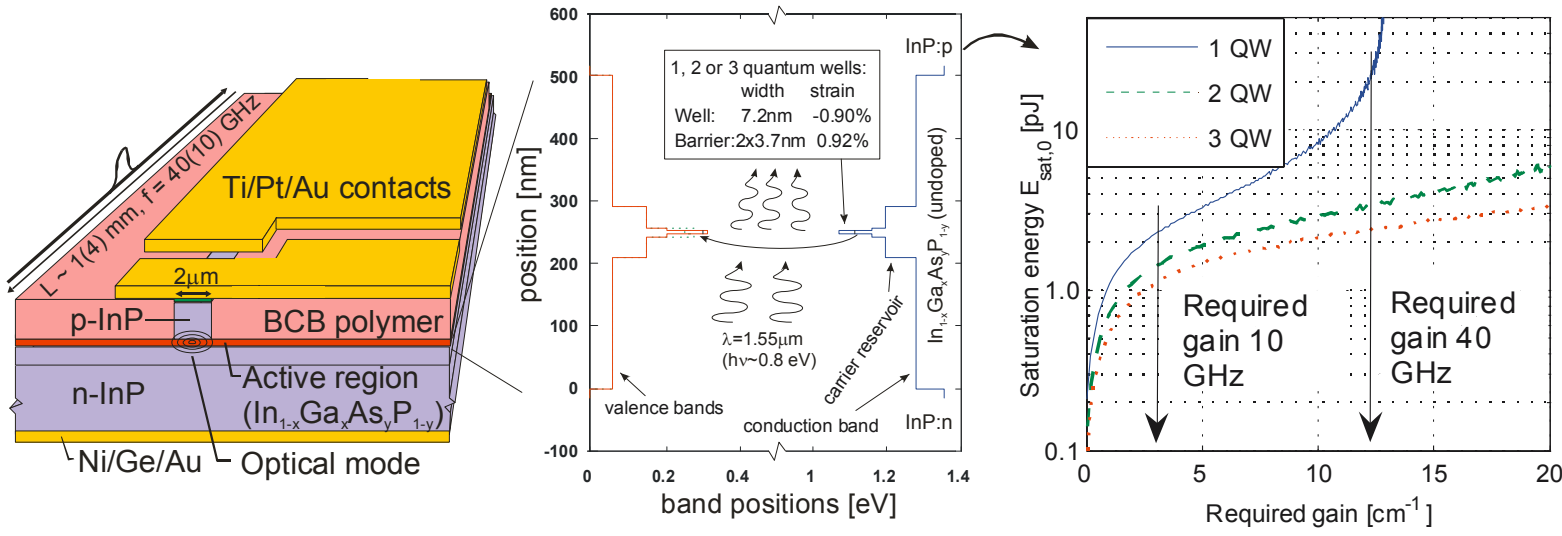

Figure 1. Left/Middle: Schematic of the device with a blowup of the active layers. Right: Calculated gain saturation energy versus required net gain in the device. The approximate required gain for HR coated lasers of different frequencies is indicated.

The work reported in this paper was supported by the Danish Technical Research Council through the SCOOP programme and the talent project 26-04-0060. 
Table 1. Summary of operating conditions for selected results from 10 and $40 \mathrm{GHz}$ lasers. Output power includes $3 \mathrm{~dB}$ coupling loss.

\begin{tabular}{|l|c|c|c|c|c|c|}
\hline Number of quantum wells & 1 & 2 & 1 & 2 & 3 & \\
\hline Device / absorber length & $4260 / 100$ & $4260 / 55$ & $1070 / 60$ & $1070 / 55$ & $1070 / 50$ & $\mu \mathrm{m}$ \\
\hline Coating & HR & HR\&AR & HR & HR & HR & \\
\hline Gain current, absorber bias & $50,-3.5$ & $50,-3.0$ & $191,-2.7$ & $190,-3.8$ & $240,-4.0$ & $\mathrm{~mA}, \mathrm{~V}$ \\
\hline Frequency, RF power & $9.930,24$ & $9.973,24$ & $39.78,26$ & $39.58,26$ & $39.53,26$ & $\mathrm{GHz}, \mathrm{dBm}$ \\
\hline Center wavelength & 1531 & 1556 & 1531 & 1547 & 1562 & $\mathrm{~nm}$ \\
\hline Pulsewidth (w/ added dispersion) & $1.8(0.55)$ & $1.4(0)$ & $1.1(0.65)$ & $1.2(0.65)$ & $1.4(0.65)$ & $\mathrm{ps}(\mathrm{ps} / \mathrm{nm})$ \\
\hline Time bandwidth product & 0.42 & 0.58 & 0.38 & 0.51 & 0.61 & $($ FWHM) \\
\hline Fibercoupled output power & 0.5 & 1.6 & 9.2 & 8.7 & 9.0 & $\mathrm{~mW}$ \\
\hline
\end{tabular}

The epitaxial structures of the active region of the lasers are shown in Fig. 1 (middle). Thick undoped layers are used to lower the waveguide loss and devices with 1, 2 and 3 quantum wells are fabricated. The absorber facet is high-reflection coated on all lasers to increase the intensity in absorber.

In Fig. 1 (right), a calculation of the gain saturation energy versus the required net gain is shown. The gain saturation energy is the pulse energy where the gain is reduced to zero. In practice, only a limited gain saturation will be tolerated since it results in both pulse broadening and chirp of the emitted pulses. For only a $10 \%$ reduction in gain, the maximum pulse energy should be $1 / 10$ of the value in Fig. 1. For a laser the working point on the gain curve is fixed by the loss when the laser is operating, which means that the gain saturation energy is dependent on the number of wells (cmp. Fig. 1 right). For the $40 \mathrm{GHz}$ lasers the required gain is close to the maximum available using a single well which is the optimum as see in the strongly increasing gain saturation energy. We would therefore expect that the pulseshaping is more gentle for the $1 \mathrm{QW}$ lasers which would translate into less chirp, a higher efficiency and less noise. The $10 \mathrm{GHz}$ lasers are four times longer than the $40 \mathrm{GHz}$ lasers and the required gain coefficient is therefore quite low as indicated in Fig 1 . We would therefore expect a lower output power and smaller difference between the different epitaxial structures for these devices. More details on the influence of the epitaxial design can be found in $[3,4]$

\section{RESULTS FOR 10 GHz LASERS}

The lasers are mounted with the absorber section bonded to a coplanar electrical waveguide, which allows modulation to be applied for the synchronization to an electrical clock. Operating conditions and pulse properties for typical performance close to the optimum operation point is shown in table 1 . The pulse performance of the $10 \mathrm{GHz}$ lasers is actually better for a high- and low (5\%) reflection coated 2 QW laser (see Fig. 2 left) than for the $1 \mathrm{QW}$ laser. This is because the difference between the gain saturation energies is not especially large so that the more efficient modulator in the $2 \mathrm{QW}$ device gives shorter pulses. In Fig. 2 (right) the absolute phase noise is shown, measured with a photodiode/spectrum analyzer combination, detecting the pulse train directly at $10 \mathrm{GHz}$. At low offset frequencies the laser follows the electrical clock (synthesizer) completely as would be expected, while the laser noise is visible at offsets $>1 \mathrm{MHz}$ before the noise floor is reached at $200-300 \mathrm{MHz}$. The noise for the $2 \mathrm{QW}$ device is higher than that for a $1 \mathrm{QW}$ device due to the
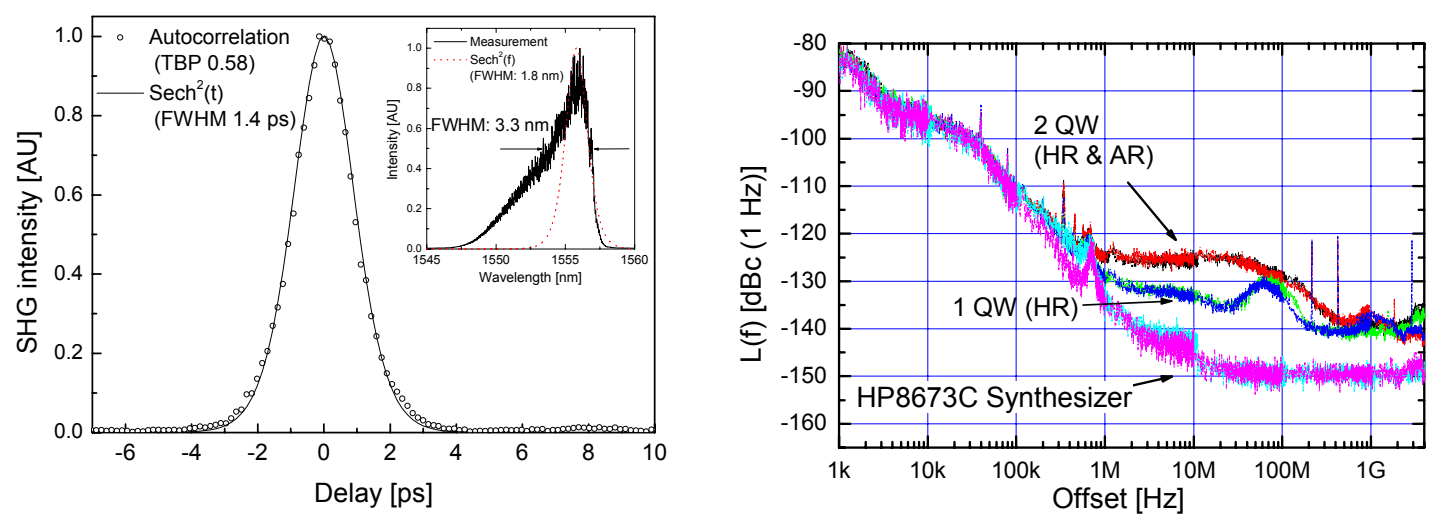

Figure 2. Left: Autocorrelation of a 2 QW hybridly mode-locked laser with the optical spectrum inserted. Right: Absolute phasenoise measurement for 1 and $2 \mathrm{QW} 10 \mathrm{GHz}$ lasers. 

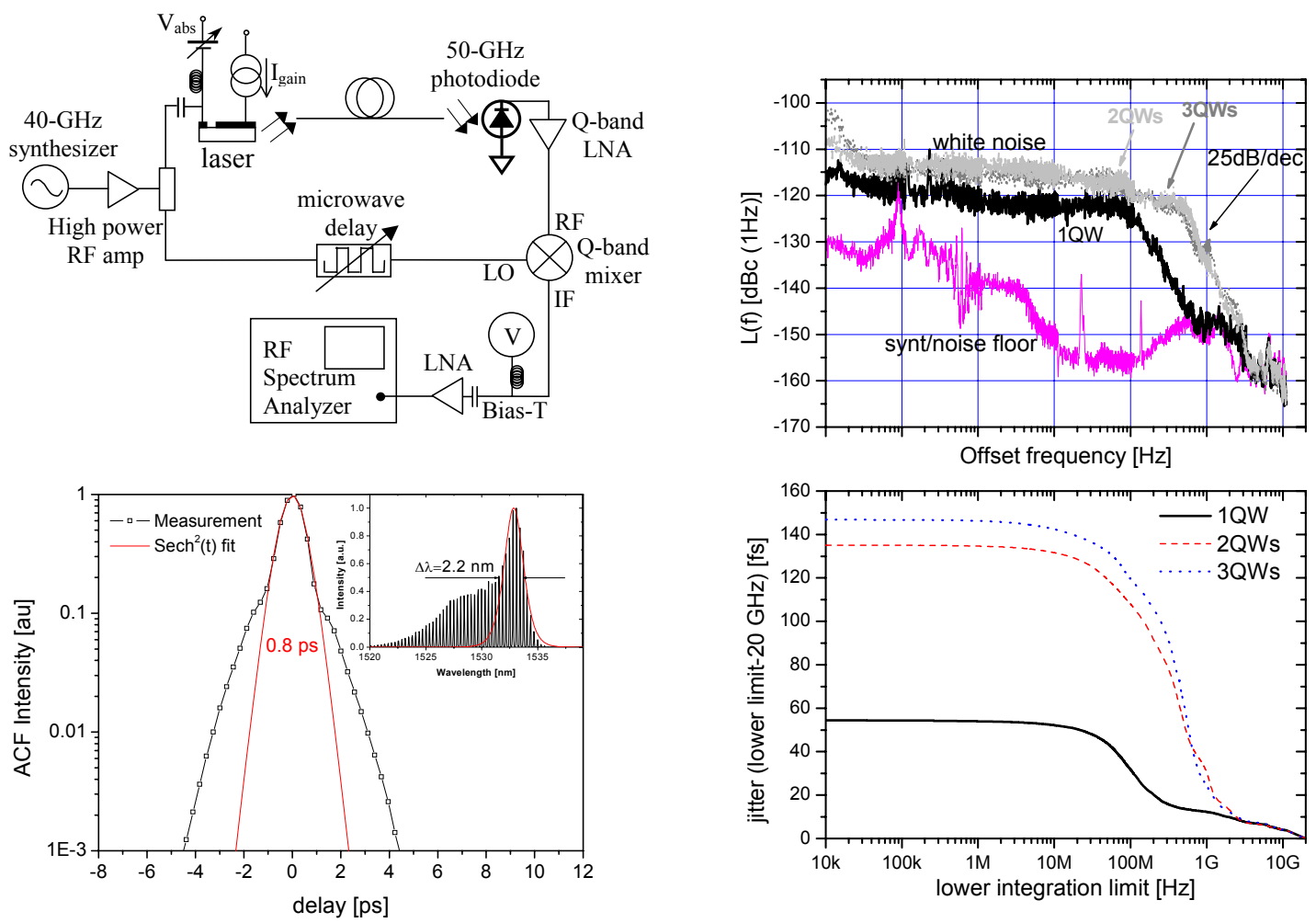

Figure 3. Top left: Residual phase noise measurement setup. Right: Residual phase noise measurement result and integrated jitter from a variable lower limit to the Nyquist frequency. Lower left: Autocorrelation of low noise pulse from $1 \mathrm{QW}$ device at "optimal" compression (0.9 ps/nm). Inset: optical spectrum showing excess spectral components on the high energy side.

higher spontaneous emission noise and stronger pulseshaping for the $2 \mathrm{QW}$ device. If the gain current is increased, the jitter is lowered slightly, but the pulse is broadened and more chirped which is consistent with the low gain saturation energy of the gain medium at the low required gain.

For demultiplexing and optical signal processing it is the phase difference between the data signals and the recovered clock that is of importance. For these applications one would use a wide-bandwidth clock-recovery (CR) circuit to capture as much as possible of the slow jitter and the remaining high-frequency noise is what is important. This "uncorrelated" jitter should be less that $1 / 12(1 / 14.2)$ of the bit period for a $10^{-9}\left(10^{-12}\right)$ bit error rate [5]. For the data in Fig 2, the integrated jitter in the range $1 \mathrm{MHz}-5 \mathrm{GHz}$ is $\sim 195$ fs for the $1 \mathrm{QW}$ device and $\sim 300$ fs for the $2 \mathrm{QW}$ device but this includes a large contribution from the noise floor of the measurement.

\section{RESULTS FOR 40 GHz LASERS}

For the $40 \mathrm{GHz}$ lasers the length of the device is only $1 \mathrm{~mm}$ and the required gain including the absorber loss is close to the maximum available for a 1-QW device as seen in Fig. 1 (right). This indicates that it will be possible to operate it at higher powers, which will ensure low jitter operation while keeping short pulses.

If absolute phase noise measurements are used to evaluate the noise of the $40 \mathrm{GHz}$ lasers the effective noise floor of a $50 \mathrm{GHz}$ electrical spectrum analyzer $(\sim-125 \mathrm{dBc}(1 \mathrm{~Hz})$ for our HP8565E) will mask the contribution from the laser completely [6]. Residual phase noise measurements (Fig. 3 top, left), where external mixing of the detected pulse train with the reference clock is used before the spectrum analyzer, is a way for solving the measurement problem $[1,7]$. Since this measurement is relative to the synthesizer the contribution from the latter at long timescales will not appear because the laser tracks this part of the jitter as shown for the $10 \mathrm{GHz}$ device. This is an advantage since the noise we are interested in for practical purposes is the difference between the clock and laser as noted earlier. More importantly, because the carrier has been removed in the external mixing we can amplify the noise bands and send them into the spectrum analyzer without saturating its mixer. We are therefore able to follow the fall-off of the side-band noise several decades as shown in Fig. 3 (top right). Also, when we evaluate the rms jitter we can now integrate all the way to the Nyquist frequency $(20 \mathrm{GHz})$ and thus include the pulse to pulse jitter, which will introduce unavoidable penalties in the optical signal processing. As shown in Fig. 3 (lower right), a value of less than $60 \mathrm{fs}$ for the $1 \mathrm{QW}$ device is seen (integrated in the full measurement bandwidth) which is sufficient for Tbit/s transmission systems. The lack of intracavity filtering limits the spectral quality of the lasers as shown in the inset of Fig. 3 (lower left) and give rises to the shoulders 
on the autocorrelation for compressed pulses. It should be noted that while the pulse width and spectrum can be modified fairly easy outside the laser cavity, this is not the case for the jitter.

\section{CLOCK RECOVERY USING MONOLITHIC MODELOCKED LASER}

As an example of an application for the lasers, a $10 \mathrm{GHz}$ clock-recovery (CR) circuit based on a phase-locked loop using four-wave mixing (FWM) in a semiconductor optical amplifier (SOA) is shown in Fig. 4. This prescaled CR setup, extracts a $10 \mathrm{GHz}$ clock from a high bit-rate pulse train, and uses only semiconductor components meaning that it can be integrated on a single chip.

A 40-320 Gbit/s optical time division multiplexed sequence is launched into a SOA along with an amplified and filtered $10 \mathrm{GHz}$ pulse train from a MMLL. The FWM product is extracted and fed to a feedback loop which controls an oscillator which drives the MMLL. In Fig. 4 (right) the error signal is shown when the feedback loop is open and the control pulses scans across the data pulses. A clear signal, especially for the lower repetition rates is seen, which can be used to lock the clock. Due to the filtering and fiber in the loop the laser pulse is almost 4 ps which is not enough to resolve the $320 \mathrm{Gbit} / \mathrm{s}$, but successful locking to up to $160 \mathrm{Gbit} / \mathrm{s}$ has been achieved [8].
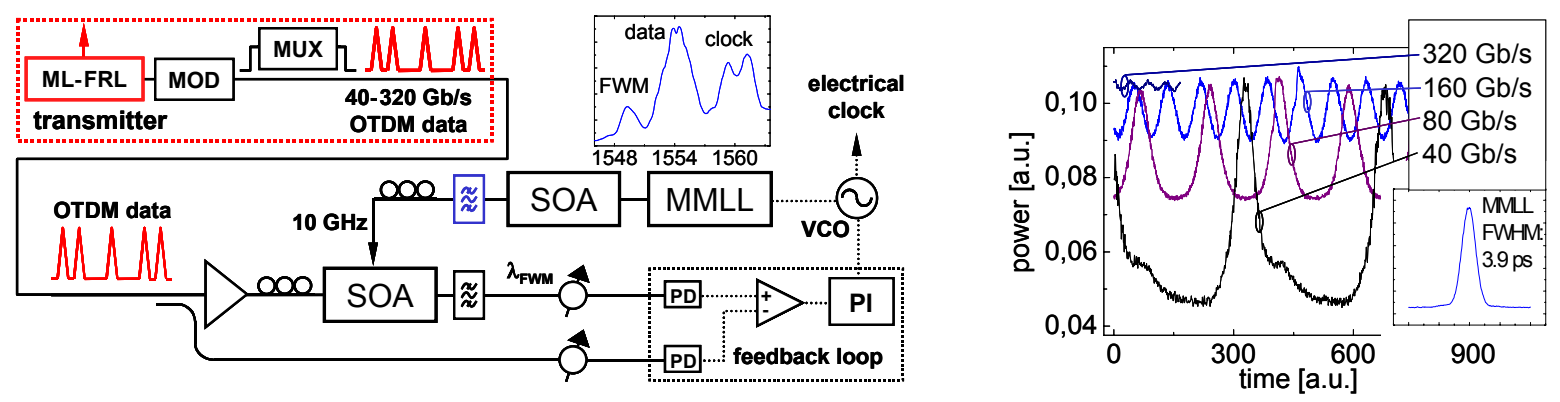

Figure 4. Left: High-speed clock recovery set-up. Right: Error signal at 40, 80, 160 and 320 Gb/s. Inset: Clock pulse shape.

\section{CONCLUSIONS}

We have shown that the use of few quantum wells in monolithic mode-locked lasers enables both low noise and increased output power for 10 and $40 \mathrm{GHz}$ lasers. Such lasers can fulfil the requirements for terabit optical time division multiplexed communication systems.

\section{REFERENCES}

[1] D.J. Derickson, P.A. Morton, and J.E. Bowers: Comparison of timing jitter in external and monolithic cavity mode-locked semiconductor lasers, Appl. Phys. Lett., vol. 59, pp. 3372-3374, 1991.

[2] S. Bischoff et al.: Pulse-shaping mechanism in colliding-pulse mode-locked laser diodes, Appl. Phys. Lett. vol. 67, pp. 3877-3879, 1995.

[3] K. Yvind et al.: Design and evaluation of mode-locked semiconductor lasers for low noise and high stability, OptoIreland Proceedings of SPIE, Paper 5825A-4, 2005.

[4] K.A. Williams, M.G. Thompson and I.H. White:Long-wavelength monolithic mode-locked diode lasers, New Journal of Physics 6, no. 1, 179 (2004).

[5] K. Yvind et al.: Low-Jitter and High-Power 40 GHz All-Active Mode-Locked Lasers, Phot. Tech. Lett., vol. 16. pp. 975-977, 2004.

[6] M. Jinno: Effects of crosstalk and timing jitter on all-optical timedivision demultiplexing using a nonlinear fiber Sagnac interferometer switch, IEEE J. QE, vol. 30, pp. 2842-2853, 1994.

[7] L.A. Jiang et al.: Quantum-limited noise performance of a mode-locked laser diode, Optics Letters, vol. 27, pp. 49-51, 2002.

[8] L.K. Oxenløwe, et al.: Pre-scaled clock recovery with compact semiconductor devices for ultra high-speed OTDM systems, in Proc ECOC 2004, paper We3.5.2, Stockholm, Sweden, 2004. 